\title{
Research into Whistleblowing: Protection Against Victimisation
}

\author{
Inez Dussuyer, Anona Armstrong \\ Victoria University, Australia \\ Russell Smith \\ Australian Institute of Criminology, Australia
}

\begin{abstract}
'Blowing the whistle' is fraught with risk and this is increasingly recognised by the widespread adoption of whistle-blower legislation to protect the whistle-blower. This paper reviews current legislation, the literature on victimisation of whistle-blowers and reports the results of a study of whistleblowers. Interviews conducted with whistleblowers showed that their experience is usually negative. They become 'victims' of a range of harms, including loss of employment, bullying and harassment and emotional distress. The results have implications for the successful operation of the new disclosure laws introduced by the Australian and State governments.
\end{abstract}

\section{Key Words}

Whistleblowing. Public sector, Private sector, legislation, Protection

\section{Introduction}

In democratic societies, governments, public sector organisations and others who spend the public 'purse' it is generally accepted that they should be accountable to the wider public. Accountability occurs through institutions including Parliament, the courts, integrity bodies such as the Ombudsman and related accountability mechanisms, and through associated governance regulations and guidelines. However, calling people to account can only happen if there is information and evidence. Research (Armstrong 2014) suggests that those who know most about wrongdoing ${ }^{1}$ are often those closest to the action. These people have been termed 'whistle-blowers' if they decide to report the wrongdoing. 'Blowing the whistle' however, is fraught with risks and this is increasingly recognised by the widespread adoption of whistle-blower legislation to protect the whistle-blower. Many questions are raised by whistleblowing (Dussuyer, Mumford and Sullivan 2011). What does it mean to 'blow the whistle'? What kinds of whistle-blowers are there? What motivates a person to 'blow the whistle'? Do different kinds of whistleblowing require different responses? What are the difficulties experienced by whistle-blowers? For those who receive their reports, what are their responsibilities? To whom should organisations be accountable for how they handle whistle-blower allegations? What are the experiences

Copyright (C) 2015 Victoria University. This document has been published as part of the Journal of Law and Governance in both online and print formats. Educational and non-profit institutions are granted a non-exclusive licence to utilise this document in whole or in part for personal or classroom use without fee, provided that correct attribution and citation are made and this copyright statement is reproduced. Any other usage is prohibited without the express permission of the publisher. of whistle-blowers after reporting wrongdoing and what is the impact on the organisation? It is these last questions that are the focus of the present study.

\footnotetext{
1 'Wrongdoing' is the term preferred in this paper to cover misconduct, corrupt conduct, illegal behaviour and other forms of non-compliance.
} 


\section{Background}

A frequently used definition of whistleblowing in the research literature is:

The disclosure by organisational members (former or current) of illegal, immoral or illegitimate practices under the control of their employers, to persons or organizations that may be able to effect action. Micali, Near and Dworkin (2008).

Increasingly however, the term 'whistle-blower'2 according to some (Armstrong \& Francis 2014) has pejorative connotations, and is replaced by terms such as ' complainant', 'respondent', reporter of public interest', ' discloser', or 'person making allegations or raising concerns'. Thus in the Victorian Public Interest Disclosure Act 2013 (PID Act) what was 'whistleblowing' in the previous Act is now a 'public interest disclosure' defined as a disclosure of information, by a public official, that is:

- a disclosure within the government, to an authorised internal recipient or a supervisor, concerning suspected or probable illegal conduct or other wrongdoing (referred to as "disclosable conduct");

- a disclosure to anybody, if an internal disclosure of the information has not been adequately dealt with, and if wider disclosure satisfies public interest requirements; or

- a disclosure to anybody if there is substantial and imminent danger to health or safety; or

- a disclosure to an Australian legal practitioner for purposes connected with the above matters.

The act of blowing the whistle and the person who does this, arouses a number of conflicting views and responses (Francis 2015; Dussuyer et al 2011). Whistle-blowers have often taken action only after a lot of 'soul searching' and a desire for change but their colleagues may feel threatened, guilty or shamed and management of an organisation may focus more on the whistle-blower than on the alleged perpetrator of the wrongdoing. It has been widely reported that in many cases it is the whistle-blower who ends up being victimised and subject to mistreatment and retaliation ${ }^{3}$. The media also regularly reports on instances where whistle-blowers have been treated poorly as a result of reporting on wrongdoings.

The purpose of this paper is to describe a study of a self-selected sample of whistle-blowers after they reported wrongdoing in their workplace, from the point of view of what they experienced through qualitative interviews, and also of those who handle and manage whistle blower reports, the 'disclosure coordinators', through an on-line survey. The focus of the present study is to identify:

- What is the nature and extent of victimisation experiences of whistle-blowers who report wrongdoing in the work place

- What elements are protective against victimisation when blowing the whistle, and

- What are effective measures to protect whistle-blowers from victimisation?

\section{Protecting the whistle-blower through legislation}

Whistle-blowers in the public and private sectors are afforded protection by legislation. Most legislation in Australia specific to protecting the whistle-blower is designed to protect the members of the public sector (Bowden, 2014, Brown 2013, Armstrong \& Francis 2013). Protection for whistle-blowers has been introduced in Public Disclosures (PD) Acts by all Australian States and at the national level since the 1990s (Armstrong and Francis 2014). Most recently legislation was introduced in Victoria in 2012 when the Whistle-blower Protection Act 2001, previously under the jurisdiction of the Ombudsman, was repealed and replaced by the Independent Broad-Based Anti-Corruption Commission Act 2011 and

\footnotetext{
${ }^{2}$ Translations of 'whistle-blower' into French - 'lanceur d'alerte' and Dutch - klokke luier' evoke colourful images as does the English term.

${ }^{3}$ Various terms have been used to describe the negative outcomes experienced by whistle-blowers after reporting wrongdoings - retaliation, victimisation, detrimental action and mistreatment. In this study the term 'victimisation' is preferred.
} 
the Protected Disclosure Act 2012 No. 85 of 2012 (Government of Victoria). The Victorian Independent Broad-Based Anti-Corruption Commission $\left(\mathrm{IBAC}^{4}\right)$ was established in 2013 with its principal function to identify, investigate and expose serious corrupt conduct, and police personnel misconduct; and also with responsibility for whistleblowing and the investigation of public interest disclosures which covers such activities as poor oversight of funds, improper use of equipment and property, misappropriation of assets, improper use of authority and position. The IBAC legislation goes further than mismanagement of public resources to also include conduct that poses risk to public health or safety or the environment. Protection for whistle-blowers by IBAC involves both having appropriate procedures in place to manage the whistle-blower process and specific initiatives to protect the whistle-blower. Thus in 2013 IBAC published Guidelines for Protected Disclosure Welfare Management and Guidelines for Making and Handling Protected Disclosures which together provide the framework and rules for compliance with the Protected Disclosures Act and procedures for the protection of whistleblowers against liability for breaches of statutory confidentiality of information and breaches of confidence. IBAC also holds regular forums of 'disclosure coordinators' who handle whistle-blower reports in the public sector organisations.

Legislation to protect whistle-blowers in the private sector is more diffuse; the Corporations Act includes some legislation; Standards Australia has issued a Standard for whistle-blower protection, and the Australian Securities Exchange listing rules requires voluntary compliance. Less specific is protection afforded by other Acts. Whistle-blowers in the private sector in Australia are protected by provisions in the Australian Corporations and Securities Act (Australian Government, 2001, Part 9.4AAAA) that is administered by the Australian Securities and Investment Commission (ASIC). The Act requires a disclosure to be made to ASIC, a member of the company's audit team, a director, secretary or senior manager of the company or a person authorised by the company to receive the disclosure.

To be protected by the Corporations Act a whistle-blower must be an officer (usually that means a director or secretary) of the company; an employee of the company; or a contractor (or employee of a contractor) who has a current contract to supply goods or services to the company. Protection provides that the persons making disclosures cannot be subjected to civil and criminal liability, termination of employment, reduction in employment conditions, the enforcement of contractual remedies and /or liability for defamation as a result of the disclosure. Victimisation or threat of victimisation is prohibited and, should it occur, the organisation or person issuing the threat can be liable to compensate the victim for damages. Bowden (2014) notes that further issues need to be addressed: managing vexatious whistle-blowers, types of wrongdoings need to be expanded, and that ASIC appears to be an inappropriate agency to deal with protection and support for whistle-blowers.

The Corporate Governance Standards issued by Standards Australian International (2003) includes the Standard AS8004-2003 Whistle-blower Protection Programs for Entities. The Standard recommends that a whistle-blower be given a guarantee of anonymity, although under the Corporations Act whistleblowers must identify themselves, and persons making anonymous reports are not protected under the Act. While the Act affords whistle-blowers some protection, the officers to whom a report is made are not protected if they fail to respond adequately to a whistle-blower's report. Bowden (2014) reported that the ASX provisions are not mandatory and found that by 2000 only 54 per cent of the ASX companies had a formal detailed whistle-blower program. Whistleblower protection is also offered to the business sector through the Australian Competition and Consumer Commission (ACCC) and the Australian Securities and Investment Commission (ASIC) legislation. Some of the problems identified with legislative protection of whistle-blowers (Armstrong \& Francis 2014; Brown \& Roberts 2011) are that it places limitations on whistle-blowers going to the public media (most organisations want to keep bad news 'in house') and whistle-blowers are advised to keep their allegations 'confidential'. Whistleblower legislation also often requires that reporting of wrongdoing must first be made internally within

\footnotetext{
${ }^{4}$ IBAC is constituted as a body independent of the Crown with its employees covered by the Public Sector Act 1994. A further Act, the Victorian Inspectorate Act 2011, created the Victorian Inspectorate, whose purpose is to monitor IBAC's compliance with relevant laws, access IBAC's policies and procedures and investigate and assess complaints against IBAC.
} 
the whistle-blower's organisation, and only as a last resort, going to an external higher authority. In many cases whistle-blowers who desire to remain anonymous risk having their identity known as the origin of information can be readily traced back to the source.

\section{Understanding why whistle-blowers are victimised}

Research has identified factors which are associated with the whistle-blower decision to take action when wrongdoing is observed. These include their perception of how the wrongdoing is viewed by peers/managers and by the organisation, their ethical values, the perceived seriousness or significance of the wrongdoing and the expectations of what will happen if they disclose the wrongdoing. Research shows that people who blow the whistle can be motivated by a desire to 'do the right thing' and correct a 'wrong', and many whistle-blowers report wanting to live in a transparent, ethical and trusting work place. A recent example (reported in Armstrong and Francis, 2014) compared and contrasted the good intentions and the practical consequences of deciding to blow the whistle. The whistle-blower's personal account of his experience after reporting wrongdoing indicated that he was committed to his organisation and was distressed by the way he was treated, that is, sidelined, ignored and finally having no choice but to leave the organisation. Bowden $(2014$, p.11) captures the essence of the problem the whistle-blower faces: 'If we are to assess by the extent of the ethics of an action, then we must rank loyalty to the wider community or the ethical precepts of society, at a higher level than loyalty to an employer. The whistle-blower is making a judgement of the harm he or she may be inflicting on the organisation by exposing a wrong, balanced against the alternative of keeping quiet'.

Further research shows that employees who have blown the whistle are often loyal to an organisation and would rather have a wrongdoing corrected by raising the issue within their organisation ${ }^{5}$ (Tsahuridu and Vandekerkhove, 2008). Others report that the workplace culture (Francis 2015), and the characteristics of the discloser and the wrongdoer are highly relevant (Ethics Research Centre, 2013).

In an important UK report about how whistle-blowers were mistreated in the National Health Service (NHS), Francis (2015) found that 'dubious motives' can be attributed to the whistle-blower, such as not acting to address poor performance, or that the disclosure was allegedly motivated by revenge, 'mental problems' or other ulterior motives, and these may have been used as an excuse for avoiding addressing public interest concerns by the organisation. Many whistleblowers have good intentions and do not anticipate the unintended consequences of their disclosure that may come from work colleagues or managers, such as viewing them as "snitches" or not part of the team. Within organisations, whistleblowers maybe perceived as threatening the status quo, and not only by the people involved in misconduct but also by their colleagues and managers who may feel threatened by the disclosures. It becomes difficult to know who to trust and creates feelings of insecurity, especially if people who raise concerns do not feel valued for doing so, or worse, are 'punished' (Francis 2015).

That whistle-blowers suffer mistreatment and harm after speaking out about wrongdoing has been widely reported (Francis 2015). Examples of victimisation experienced by persons reporting wrongdoing within organisations, included poor performance appraisal, failure to promote, denial opportunities for training, intimidation, bullying, harassment, assignment to less important duties, transfer to lesser roles, marginalisation, isolation at work, blackmail, buying them off, declared mentally unfit for work, setting impossible work assignments and non- renewal of contract. Brown et al (2008) in a major study of whistleblowing in the Australian public sector, found mistreatment was often by management. These authors also noted that mistreated whistle-blowers were not more likely to be trouble makers, disgruntled employees or persons predisposed to conflict that those treated well or the same. Brown et al (2008) collected and analysed survey data from 7,663 public agencies. It was found that 'contrary to some stereotypes it is not inevitable that a whistle-blower will suffer mistreatment from co-workers or management as a result of reporting wrongdoing, even if reporting is frequently a difficult and stressful experience' (xxvii). These authors further reported that 78 per cent of whistleblowers said they were treated well or the same as a result of reporting, while 22 per cent said they were treated badly (although it was noted that whistle-blower mistreatment varied greatly between agencies). 
However, an estimated 62 per cent of all whistle-blowers had suffered increased stress as a result of reporting, with 43 per cent reporting extreme stress.

The frequency of victimisation against whistle-blowers has reportedly ranged from a high of about 90 per cent down to 22 per cent (Bowden 2014). Bowden notes that victimisation may be reducing over time as the higher rates are from older studies. As policies and legislation are now in place to protect whistle-blowers from such behaviour; and the use of internal whistleblowing systems has developed, whistleblowing may be perceived as an important element in improving organisational governance.

While the workplace and ethical culture of an organisation is important if whistle-blowers are to feel confident in speaking up, these factors may also be relevant in determining whether a whistle-blower will be victimised. If the workplace culture does not support an ethical behaviour, transparency and integrity, and the perception is that no action will be taken, people will not risk speaking out. In the recent UK report (Francis 2015) it was found that there is a general perception that speaking up can lead to victimisation or lack of action. A reluctance to raise concerns was often associated with workplace culture of bullying or harassment behaviour. In many cases reported in the media, the immediate response of organisations to a whistleblower appears to be one of covering up the wrongdoing in order to safeguard the reputation of the organisation. ${ }^{6}$

Research into risk factors for victimisation of whistle-blowers (Near \& Miceli 1996) has identified four categories - the personal characteristics of the whistle-blower (such as gender, socio-demographic differences), organisational variables (such as size of the work group, structure), characteristics of the wrongdoing (seriousness, systematic) and the power and status of the wrongdoer (seniority, tenure). As noted by Brown et al (2008), the range of risk factors confirms the complexity of whistleblowing cases and makes it difficult to help identify where preventive efforts should be focused.

By obtaining from the whistle-blowers themselves descriptions of what they have experienced, and from disclosure coordinators who receive and manage whistle-blower reports in organisations, the present study can highlight aspects which could assist improving the outcomes for people who speak up about wrongdoings in the workplace when others remain silent.

\section{Study approach to investigating victimisation of whistle-blowers}

It was expected that obtaining the participation of whistle-blowers would be a difficult task and it was considered that being able to obtain between 20-30 qualitative interviews would provide a reasonable sample under the circumstances. Following a number of discussions with and advice from the Victorian Ombudsman's office, IBAC and other organisations who are in contact with whistle-blowers, and having obtained the approval of the Research Ethics Committee, it was decided to approach STOP line, an independent 'hotline' which provides an external service for reporting and management of disclosures of workplace crime, corruption or misconduct for private and public sector organisations. Whistle-blowers are assured by STOP line that they can maintain their anonymity by contacting STOP line, and the disclosure co-ordinators from client organisations work with STOP Line to formulate appropriate responses. While much research in Australia on whistleblowing has been focused on the public sector, it was possible through the STOP line database to include whistle-blowers from the private sector.

STOP line agreed to assist and collaborate with the researchers. It sent an email invitation to participate in the research to all whistle-blowers on its database of some 500 persons who had contacted them over

\footnotetext{
${ }^{6}$ This has been found by Australian Committees of Inquiry into child abuse where executives of institutions did not report sex abuse allegations to the legal authorities. For example, the Church institution has been accused of misleading victims by deliberately relocating priests accused of abuse instead of removing them from their positions. Whistle-blower policeman Peter Fox says he was told to stop investigating alleged abuse by priests (Reid, 2013).
} 
the last 4 years to report wrongdoing 7 . The invitation explained the aims of the study, what was involved, how confidentiality was to be protected and how to contact the researchers directly. STOP line found in the course of sending the invitation that many emails on its database were no longer active, so that a valid set of 200 emails was obtained. From these, some 20 expressions of interest were received by the researchers, with 12 interviews conducted (as at February 2015). The process of making contact and arranging a time for interview with the whistle-blowers was slow and protracted, often requiring several emails or telephone calls with further explanation of the research aims, reassurance about confidentiality and what the research was to be used for.

Qualitative interviews with whistle-blowers were mostly conducted by telephone, as a majority were based outside Melbourne. The procedure for the interview was to email the ethics approved Informed Consent Form and the Participants Information Sheet, followed by arranging a suitable time for the interview. Care was taken to assure whistle-blowers of the confidentiality of the interview and the need to ensure that the conversation was conducted in private. Qualitative interview questions focused on the experience of the whistle-blower and covered general background of the workplace/organisation and of the whistle-blower, their role; details of the actual wrongdoing incident(s), followed by what steps were taken to report the matter and then what happened subsequently. The interview attempted to follow the sequence of events, like 'beads on a string', in order to understand the whistle-blowers' experiences and the reactions to the reporting of wrongdoing.

\section{Methodological limitations}

- Whistle-blowers interviewed for the study are self-selected, and given the focus of the research it was highly likely that any whistle-blowers agreeing to participate would have had negative experiences following their reporting of wrongdoing; there was no information from whistleblowers who had been well treated (See Brown et al 2008). Hence the sample interviewed are biased towards having been victimised.

- There was a low response rate (around 10 per cent to date) to the invitation to participate in the research, which limits the conclusions that can be drawn from the study. This may be partly due to many whistle-blowers not using their original emails with which they had contacted STOP line; it could also be that length of time (up to 4 years ago) since the whistleblowing had occurred made participation in the research less salient to many.

- It was found that many whistle-blowers lived outside Melbourne, hence interviews were conducted by telephone and which limited the nature of the qualitative interview and did not always enable fuller comments to be provided by the whistle-blowers.

- Would the whistle-blowers interviewed meet the IBAC criteria for protected disclosures? It is unlikely that any of the interviewees to date would meet the serious misconduct threshold. While whistle-blowers reported a wide range of wrongdoings, none would appear to meet the stringent requirements for a formal investigation by IBAC to be initiated as it can only investigate serious indictable offences. Thus the IBAC requirement for disclosures to possess prima facie evidence of serious corrupt conduct is a high threshold to start an independent investigation. This means that in the case of the whistle-blowers interviewed in this study and who have experienced mistreatment, they would not be able to be protected by the legislation, even though they have reported suffering victimisation and they experienced significant negative consequences as a result of having reported wrongdoing in their workplace. It would appear that formal protection through the whistle-blower legislation is not available to them.

\section{Preliminary findings ${ }^{8}$}

\footnotetext{
${ }^{7}$ STOP line (www.stopline.com.au) is an independent, confidential toll free hotline service for the receipt of disclosures relating to corruption, criminal activity, serious misconduct or improper behaviour in the workplace. It was founded by former Victoria Police officers based in Victoria but has client organisations across Australia. It also provides investigative service to the private and public sectors.

${ }^{8}$ Based on 12 completed interviews to date.
} 
The whistle-blowers interviewed came from a wide range of employment sectors - these included public and private organisations, some large, Australia-wide, including some based in remote locations, while others were middle range in size. A number of whistle-blowers interviewed were on contract or employed as casual workers with no permanent employment status. More females (9/12) than males were among those interviewed. Their ages ranged from an estimated 30-60 years. In terms of their job role in the organisations, most were professionally qualified or skilled tradespersons, and generally from middle management levels.

The wrongdoing reported by the whistle-blowers ranged from deception, fraud, such as in falsifying timesheets and leave records, to bullying and harassment, non-compliance with safety regulations placing workers at risk, sexual discrimination and improper recruitment and promotion procedures.

Reporting of the wrongdoing was made internally in the first instance, most often to their immediate supervisor or to the human resource manager; when that often led according to the whistle-blowers to no action or ...'sweeping under the carpet'... of the matter, some of those interviewed also went to the unions, which were in some cases perceived to be not independent. Several others after a number of futile attempts for action went to lawyers or to the Fair Work commissions.

The nature of the victimisation experienced was generally what previous research has found marginalisation, isolation in the workplace, setting boring or impossible tasks, poor performance reports, being singled out and abused in front of others.

The outcome for the whistle-blowers after reporting the wrongdoing was in generally negative.

The one exception was the whistle-blower who decided to take early retirement and...according to her ...'that was the best decision she had made work-wise'...several of the interviewees received compensation through the courts or through workplace payouts... 'better than nothing'... as one said. For others, the outcome was non-renewal of their contracts or dismissal and unemployment. In all cases none of the interviewees at the time of interview was still working in the same organisation.

Negative emotional impacts for individuals were reported by all of those interviewed - with many taking sick leave, need for stress and anxiety medication, and visits to GPs and with continuing lingering emotional impact about what had happened to them. Most of those interviewed however said, if they were faced again with the situation, they would not change what they had done. As one person interviewed said...'once I had done it [reported the wrongdoing] it was hugely liberating'...even after the mistreatment she received subsequently.

\section{Next steps in the research}

1. Locate more whistle-blowers through STOP line and through IBAC to achieve 20-30 completed interviews

2. Complete piloting of the disclosure coordinator survey and then send it out to private and public sector organisations from the STOP line and IBAC databases

3. Analyse data and draft report of findings by December 2015 .

\section{Concluding remarks}

The experiences of the whistle-blowers interviewed so far reveal that when wrongdoings are reported, managers or supervisors are perceived to respond less by thanking the employee for bringing it to their attention; that they will look into it and report back to them, but more to ignore what is reported or worse to make the whistle-blower a scapegoat for bringing it to their attention (as in 'shoot the messenger'). As a result, the social psychological processes in organisations when reported wrongdoings are mishandled can produce forms of psychological martyrdom and organisational trauma. It can be detrimental to the organisation or workplace and lead to an absence of psychological safety, 
creating high stress, insecurity and a non-productive work culture which in the long term can be associated with absenteeism, sick leave and high employee turnover and produce what has been termed a 'survivor syndrome' as occurs after organisational restructuring or redundancies (Wilde 2014).

\section{References}

Armstrong, A. and Francis, R.D.2014 (in press) Protecting the Whistle-blower, in B. Rider, (Ed.) Handbook on International Crimes University of Cambridge London: Routledge.

Armstrong, A. and Francis, R. D. 2014 legislating to protect the whistle-blower: The Victorian experience. The Australian Journal of Corporate Law. 29, pp.101-111.

Armstrong A. F. and Francis R.D. 2013 Protecting the Whistle-blower. Paper presented to the workshop Whistleblowing, International Symposium on Economic Crime, Jesus College, University of Cambridge, September.

Australian Government, 2001Australian Corporations and Securities Act Part 9.4AAAA, Sec.1317. Canberra, Australian Government.

Bowden, P. 2014 In the Public Interest: Protecting Whistle-blowers and Those Who Speak out Prahran, Victoria, Tilde.

Brown A.J. (Ed.) Whistleblowing in the Australian Public Sector: Enhancing the theory and practice of internal witness management in public sector organizations.Pp.121-151. Canberra, ANU EPress.

Brown, A.J. 2008 Public Interest Disclosure Legislation in Australia: Towards the Next Generation. Brisbane, Griffith University, Commonwealth Ombudsman, NSW Ombudsman and Queensland Ombudsman.

Brown, A.J. \& Roberts, P. 2010 The Australian legislative experience. In D. Lewis (ed.) A global approach to public interest disclosure legislation. Pp.56-73 Cheltenham, Edward Elgar.

Brown, A.J. 2013 Towards ideal whistleblowing legislation? Some lessons from Australia. E Journal of International and Comparative Labour Studies, Vol.2 No.3. Pages XX

Dussuyer, I., Mumford, S. \& Sullivan, G. Reporting corrupt practices in the public interest: innovative approaches to whistleblowing, In Handbook of Global Research and Practice in Corruption, eds, Graycar, A. and Smith, R. Edward Elgar, Cheltenham, UK.

Francis. Sir R. 2015 Freedom to Speak Up: An independent review into creating an open and honest reporting culture in the NHS. London, Department of Health, UK Government.

Miceli, M.P. and Near, J.P. 2013 An international comparison of the incidence of public sector whistle-blowing and the prediction of retaliation: Australia, Norway and the US. Australian Journal of Public Administration, vol. 72, no.4, pp.433-446.

Miceli, M.P. Near, J.P. and Dworkin, T.M. 2008 Whistleblowing in organizations. New York: Lea's organization and Management Series: Routledge/Taylor \& Francis.

Miceli, M.P. Near, J.P. and Dworkin, T.M. 2009 A word to the wise: How managers and policymakers can encourage employees to report wrongdoing. Journal of Business Ethics no.86, pp.379-396;

Pascoe, J. and Welsh, M. 2011 Whistleblowing, ethics and corporate culture: theory and practice in Australia, Common Law world Review, vol.40, pp. 144-173.

Pascoe 2010 Corporate Sector Whistleblowing in Australia- some empirical evidence. Keeping good companies- Journal of Chartered Secretaries of Australia vol.62, no.6, and pp.373-378.

Sarbanes-Oxley Act (SOX), An Act to Protect Investors by Improving the Accuracy and Reliability of Corporate Disclosure made pursuant to the Securities Laws and for other Purposes"

Sherron Watkins, 2006 Viewpoint: Ken Lay Still Isn't Listening. Time May 28. sherronwatkins.com. Accessed 30 May 2014.

Smith, R. and Brown, A.J. 2008. The good, the bad, and the ugly: Whistleblowing in our times in

Tsahurida, E.E. and Vandekerchehove, W. 2008 Organisational whistleblowing policies: making employees responsible or liable? Journal of Business Ethics. 82 (1), 107-118 2008

Wilde, J. 2014 Whistle-blowing and psychological safety, British Psychological Society, Chair of Working Party on Work and Health, The Guardian, 19 Oct. 2014. 